\title{
A Prospective and Observational Immunological Correlation Analysis of Non Classical with Classical Clinical Spectrum of Dengue Disease at Tertiary Health Centre
}

\author{
Authors \\ Dr N.Uma ${ }^{1}$, Dr Shivam Yadav ${ }^{2 *}$ \\ ${ }^{1}$ Medical Specialist \& Head, Department of Medicine, ABG Hospital \\ ${ }^{2}$ MD Medicine, SR Medicine, ABGH \\ *Corresponding Author \\ Dr Shivam Yadav \\ Email: shivamyadav24@gmail.com
}

\section{Introduction}

Dengue is a mosquito borne viral disease caused by Dengue virus (DEN-1, 2, 3\&4). Dengue is endemic in more than 100 countries $^{[1]}$. Dengue constitutes a major cause of pediatric morbidity and mortality in South East Asian countries ${ }^{[2]}$. Dengue fever (DF) has been reported from India over a longtime, but dengue hemorrhagic fever (DHF) was first reported in 1963 from Calcutta city $^{[3]}$. Since then several outbreaks of dengue fever have been reported from India with a major epidemic of dengue hemorrhagic fever that occurred in Delhi in 1996 when 10,252cases and 423 deaths were reported ${ }^{[3]}$. Manifestation in children and adults differ in many ways. In a study, children had higher proportion of DHF I $(42.9 \%)$ cases, whereas $51 \%$ adults were of DHF II. Some clinical manifestations, such as petechiae, melena, headache, retro-orbital pain, joint pain, myalgia, nausea and vomiting were more common in adult patients ${ }^{[8]}$. This study was undertaken to evaluate clinical profile and outcome of adult admitted with DHF/Dengue
Shock Syndrome (DSS), dengue like illnesses amongst the adult admitted ii ABG Hospital Delhi from 2017.

\section{Subjects \& Method}

This was a hospital based retrospective study. During from the year 2017 dengue positive, 100 cases suspicion of dengue fever were hospitalized in the Department of Medicine ABG Hospital, Delhi, India during the period of from 2017. An approval from the head of the department was taken. Medical records of these 100 Adult were analyzed. Criteria used for clinical diagnosis were.

\section{Probable Dengue Fever (DF)}

Acute febrile illness with 2 or more of the following manifestations:

1. Headache 2. Retro-orbital pain

3. Myalgia 4. Arthralgia

5. Rash 6. Haemorrhagic manifestations

7. Leucopenia;

\section{Confirmed DF}

Cases having positive ELISA test for Anti dengue $\operatorname{IgM}$ antibody 


\section{Dengue Hemorrhagic Shock (DHF)}

All of following must be present

1. Confirmed dengue fever through laboratory

2. Fever for 2-7 days

3. Bleeding evidenced by at least one of the following:
a. Positive tourniquet test (TT),
b. Petechiae, ecchymosis, or purpura,
c. Bleeding from the mucosa, GI tract, inj.site
d. Haematemesis or malaena
e. Thrombocytopenia $(100,000 / \mathrm{mm} 3$ or less $)$,

4. Evidence of plasma leakage due to increased vascular

Permeability, manifested by at least one of the following:

a. Rise in the haematocrit $>20 \%$ above average for age, sex \& population.

b. Drop in the haematocrit following volume replacement treatment $>20 \%$

c. Signs of plasma leakage e.g., pleural effusion, ascites, hypoproteinaemia

\section{Dengue Shock Syndrome (DSS)}

\section{Four criteria of DHF}

2. Plus signs of circulatory failure manifested as

a. Rapid and weak pulse

b. Narrow pulse pressure $(<20 \mathrm{mmHg})$

c. Hypotension for age (Sys Press $<80 \mathrm{mmHg}$ for $<5 \mathrm{yrs}$,

$<90 \mathrm{mmHg}$ for $>5 \mathrm{yrs}$ )

d. Cold, clammy skin

e. Restlessness

Thrombocytopenia was further categorized, depending on severity as those with platelet count less than 50,000/cumm and with platelet countless than 20,000/ cumm. Disease severity was assessed according to the WHO grading system:

- Grade I: Positive tourniquet test

- Grade II: Spontaneous bleeding

- Grade III: Circulatory failure

- Grade IV: Undetectable blood pressure and pulse Grades III and IV DHF also referred to as DSS.

Hemoglobin, hematocrit, platelet count and total leukocyte count was done in all cases. Platelet count was monitored as and when required in certain cases. Liver function test, renal function test were done in all those cases where it was possible. Chest X-ray and ultrasound abdomen was done in some patients. Serological diagnosis was carried out with IgM ELISA. Patients in whom the serological tests were negative but presented with characteristic features of DHF or DSS, were classified under Viral Hemorrhagic Fever and those with features of dengue fever were classified as Dengue like illness.

\section{Observations}

Total 100 cases of suspected dengue were admitted in the hospital during the study period, of these total 57 (57\%) cases came out positive out . In 7 of the cases $\operatorname{IgM}$ was positive by Card method but Negative with ELISA so these cases were not included amongst positive. The findings observed are as follows: Amongst the cases admitted adult was of 18 year of age and maximum were in the age group \& near 90 yrs.

Table 1: Agewise distribution of $\operatorname{IgM}+v e$ and Suspected Dengue cases

\begin{tabular}{|c|c|c|}
\hline Age group & $\begin{array}{c}\text { IgM+ve } \\
\text { cases }\end{array}$ & $\begin{array}{c}\text { Suspected } \\
\text { Dengue }\end{array}$ \\
\hline $\begin{array}{c}1 . \quad<20 \mathrm{yr} \\
2 . \quad 20-40 \mathrm{yr}\end{array}$ & 10 & 14 \\
\hline 3. $\quad 40-60 \mathrm{yr}$ & 19 & 25 \\
\hline $4 . \quad 60-80$ above & 05 & 20 \\
\hline
\end{tabular}

Table 2: Clinical manifestations among IgM+ve and Suspected Dengue cases

\begin{tabular}{|c|c|}
\hline Clinical Feature & IgM +ve Cases \\
\hline 1. Fever + C/R & 23 \\
\hline 2. Fever-C/R & 09 \\
3. Rashes & 10 \\
4. Anorexia & 01 \\
\hline 5. Nausea \& vomiting & 01 \\
\hline 6. Headache & 05 \\
\hline 7. Body ache & 01 \\
\hline 8. Abdo. pain & 02 \\
\hline 9. Cough \& coryza & 02 \\
\hline 10. CNS & 03 \\
\hline
\end{tabular}


Table 3: Bleeding manifestations among IgM+ve and Suspected Dengue cases

\begin{tabular}{|c|c|c|}
\hline Bleeding manifestations & $\begin{array}{c}\text { IgM +ve } \\
\text { Cases }\end{array}$ & $\begin{array}{c}\text { Suspected } \\
\text { Dengue }\end{array}$ \\
\hline $\begin{array}{c}\text { 1. Hess's Test } \\
\text { Positive }\end{array}$ & 05 & 21 \\
Negative & 20 & 20 \\
Not applicable & 11 & 42 \\
\hline 2. Petechiae & 29 & 47 \\
\hline 3. Epistaxis & 5 & 20 \\
\hline 4. Gum Bleed & 1 & 3 \\
\hline 5. Hematemesis & 3 & 15 \\
\hline 6. Malena & 4 & 16 \\
\hline 7. Hematochezia & 3 & 5 \\
\hline 8. Bruise @ inj site & 2 & 2 \\
\hline
\end{tabular}

Table 4: Evidence of fluid leakage

\begin{tabular}{|c|c|c|}
\hline Condition & IgM +ve Cases & $\begin{array}{c}\text { Suspected } \\
\text { Dengue }\end{array}$ \\
\hline $1 . \quad$ Edema & 11 & 19 \\
\hline 2. Ascitis & 06 & 14 \\
\hline 3. Effusion & 01 & 06 \\
Bilateral & 0 & 1 \\
\hline
\end{tabular}

Table 5: Incidence of organomegaly

\begin{tabular}{|c|c|c|}
\hline Organomegaly & $\begin{array}{c}\text { IgM +ve } \\
\text { Cases }\end{array}$ & $\begin{array}{c}\text { Suspected } \\
\text { Dengue }\end{array}$ \\
\hline $\begin{array}{l}\text { 1. Hepatomegaly } \\
\text { Tender } \\
\text { Nontender }\end{array}$ & $\begin{array}{c}21 \\
7 \\
11\end{array}$ & $\begin{array}{l}36 \\
30 \\
34\end{array}$ \\
\hline 2. Splenomegaly & 3 & 36 \\
\hline Diagnosis & \multicolumn{2}{|c|}{ Number } \\
\hline 1. Dengue F & \multicolumn{2}{|c|}{27} \\
\hline 2. DHF I & \multicolumn{2}{|c|}{7} \\
\hline 3. DHF II & \multicolumn{2}{|c|}{23} \\
\hline 4. DHF III & \multicolumn{2}{|c|}{2} \\
\hline 5. DHF IV & \multicolumn{2}{|c|}{2} \\
\hline
\end{tabular}

\section{Discussion}

In this study most of the cases were between 18 90 yrs of age. In a study by Faridi et al, $76 \%$ of all cases of DHF /DSS ${ }^{[10]}$. In a study by Anju et al, $45 \%$ cases presented with DHF/DSS ${ }^{[11]}$.

In our study, Dengue fever was present in 27 cases of IgM Positive out of 57 final diagnosed cases. DHF II was present in 23 of cases o IgM positive out of 57 final diagnosis while DHF I, III \& IV each were present in near $5 \%$ of cases. In a study by Dhooria et al $92 \%$ of cases presented in Grade II and $7.4 \%$ cases presented in Grade III of WHO classification. No patient presented in
Grade IV severity. Patients with Grade I disease did not require admission ${ }^{[4]}$. In a study by Ratageri et al, dengue fever was present in $18 \%$, DHF in $60 \%$ and DSS in $22 \%$ of cases ${ }^{[9]}$. In a study of 134 cases by Anju et al 67\% of cases were of DHF whereas remaining $33 \%$ were of $\mathrm{DSS}^{[11]}$.

In this study, common symptoms seen were fever with chills $\mathrm{n}$ rigors $(57.5 \%)$, fever without chills $\mathrm{n}$ rigors in $42.5 \%$ cases, vomiting (23\%), bodyache (37.5\%), abdominal pain (37.5\%), headache $(27.5 \%)$, anorexia $(2.5 \%)$, Cough n coryza $(7.5 \%)$, and CNS symptoms (15\%). Hepatomegaly was seen in 20 cases $(50 \%)$, splenomegaly was found in 3 cases $(7.5 \%)$ while pleural effusion was noted in $15 \%$ cases and all were on right side. In a study by Dhooria et al common symptoms seen were fever $(91 \%)$, vomiting $(41 \%)$, poor intake $(21 \%)$, abdominal pain(16\%) and significant bleeding $(15 \%)$. Hepatomegaly was seen in $60 \%$ of cases $^{[4]}$. Ratageri et al reported fever (100\%), vomiting (82\%), abdominal pain (61\%), restlessness $(65 \%)$, headache (22\%), and hepatomegaly (87\%)[9]. The mean duration of fever prior to admission was 5.47 days (2-12 days) ${ }^{[9]}$ which was 6 days(2-15 days) in our study. In a study by Kabra et al pleural effusion occurred in 19 patients (90\%/o), and $18(86 \%)$ exhibited each of the following: vomiting, thrombocytopenia. Hepatomegaly was observed in 15 patients $(71 \%)$ and splenomegaly in three $(14 \%)$.

In our study the most common bleeding manifestation was petechiae in $35 \%$.Significant bleeding in form of melena $(10 \%)$, hematemesis (7.5\%), heamtochezia $(7.5 \%)$, epistaxis $(12.5 \%)$, gum bleed $(2.5 \%)$ and bruises at injection site (5\%) was seen. In a study by Dhooria et al petechiae was seen in $85 \%$ of cases, melena $(6 \%)$, ecchymosis $(2.5 \%)$ and epistaxis $(2.5 \%)^{[4]}$. In a study by Ratageri et al, common bleeding manifestations were GI bleeding (22\%) and petechiae (18\%)[9]. Gastrointestinal tract was reported as the commonest site of bleeding (61\%) in a study by Ahmed et al ${ }^{[13]}$ as well as Rachel et $\mathrm{al}^{[12]}$. In our study, gastrointestinal bleeding in the form of melena, hematochezia and hematemesis 
was seen in $25 \%$ of cases. Gastrointestinal bleeding is secondary to microvascular damage leading to increased permeability (particularly when platelet function is decreased) or actual disruption and local hemorrhage ${ }^{[14]}$

The main pathogenic feature of dengue is an increase in vascular permeability leading to loss of plasma from blood vessels, which causes hemoconcentration, low blood pressure and shock. This may also be accompanied by hemostatic abnormalities such as thrombocytopenia, vascular changes and coagulopathy ${ }^{[15]}$. A drop in platelet count to below $100,000 /$ cumm and an increase of $20 \%$ or more in the hematocrit, both resulting from increased vascular permeability, are consistent findings. Other signs of plasma leakage include pleural effusion, ascites and hypoproteinemia. In the study the mean hematocrit at presentation was $28.3 \mathrm{gm} \%$ and since pre illness hematocrit was not known it was difficult to document hemoconcentration. These observations suggest that hemoconcentration may not be a good indicator for diagnosis and monitoring of fluid if pre-illness hematocrit is not known, particularly because there is a high prevalence of anemia in the population ${ }^{[13]}$.

In the current study, out of 40 cases only 6 patients $(15.5 \%)$ had platelet count over $1,00,000 /$ cumm and $50 \%$ cases had platelet count less than 50,000/cumm and $10.5 \%$ cases had platelets less than 20,000/cumm. In the study by Dhooria et al on DHF cases all patients had platelet counts less than 100,000/cumm (part of case definition of DHF), while $59 \%$ of cases had platelet count less than 50,000/cumm. There was poor correlation between thrombocytopenia and bleeding diathesis indicating thereby that the abnormal platelet aggregation rather than reduction in absolute numbers was the cause of bleeding diathesis. In the study by Kamath et al, platelet counts less than 50,000/cumm were noted in $62.3 \%^{[16]}$. Dengue infection can cause neurological manifestation ranging from nonspecific symptoms to encephalitis and rarely Guillain- Barre Syndrome ${ }^{[17]}$. Apart from abnormal neurology secondary to cerebral hypoperfusion

on account of shock other significant reasons for neurological presentations include cerebral edema, direct neurotropic effect of dengue virus resulting in encephalitis/ encephalopathy, or secondary to hepatic dysfunction and metabolic derangements such as hypoglycemia and hyponatremia ${ }^{[18-21]}$. Encephalopathy is known to occur in $0.5 \%$ of patients with $\mathrm{DHF}^{[22]}$. Malavige et al reported acute liver failure (73\%), electrolyte imbalances $(80 \%)$ and shock $(40 \%)$ as factors contributing to encephalopathy ${ }^{[23]}$. In study by Dhooria et al, of the 3 patients $(3.7 \%)$ which presented with altered sensorium, 1 patient had persistent low GSC and seizures in spite of correction of shock ${ }^{[4]}$. Soloman et al found that altered consciousness and convulsions are the major manifestations of dengue infection in $\mathrm{CNS}^{[24]}$. In our study 6 out of 40 had some CNS complaints, 3 of which had seizures and unconsciousness \& drowsiness was complained by 1 patient each while the other had irritability none of these patient had shock or dyselectrolytemia.

\section{References}

1. WHO. Dengue/dengue haemorrhagic fever. Weekly Epidemiological Report 75. 2000;24:193-200.

2. Cho-Min-Naing. Assessment of dengue hemorrhagic fever in Myanmar. Southeast Asian J Trop Med and Pub Hlth. 2000; 31(4):636-41.

3. Dengue/DHF: Trend of Dengue case and CFR in SEAR Countries. India. Available at:

www.searo.who.int/en/Section10/Section33 2/Section2277.htm. Access date: July 2007.

4. Dhooria G.S., Bhat D., Bains H.S. Clinical Profile and Outcome in Children of Dengue Hemorrhagic Fever in North India.Original Article Iran J Pediatrics Sep 2008; Vol 18 (No. 3), Pp:222-228.

5. Kabra S.K. ,Verma I.C. ,Arora N.K. ,Jain Y., \& KaIra V. Dengue haemorrhagic fever 
in children in Delhi. Bulletin of the World Health Organization, 70 (1): 105-108 (1992)

6. Riaz M.M.,Mumtaz K.,Khan M.S.,Patel J.,Tariq M., Hilal H.,Siddiqui S.A.,Shezad F. Outbreak of Dengue Fever in Karachi 2006: a clinical perspective. J Pak Med Assoc. 2009;59(6): p339-344.

7. Thomas L, Brouste Y, Najioullah F, Hochedez P, Hatchuel Y, Moravie V, Kaidomar S, King JP, Besnier F, Abel S, Carmès S, Schmitt $S$, Brihier $P$, Meunier $C$, Cardoso T, Rosine J, Quenel P, Césaire R, Cabié A. Prospective and descriptive study of adult dengue cases in an emergency department, in Martinique.Available at http://www.ncbi.nlm.nih.gov/sites/entrez

8. Kittigul L, Pitakarnjanakul P, Sujirarat D, et al. The differences of clinical manifestations and laboratory findings in children and adults with dengue virus infection. J Clin Virol. 2007; 39(2):76-81.

9. Ratageri VH, Shepur TA, Wari PK, et al. Clinical profile and outcome of dengue fever cases. Indian J Pediatr. 2005;72(8): 705-6.

10. Faridi MMA, Aggarwal A, Kumar M, et al. Clinical and biochemical profile of dengue haemorrhagic fever in children in Delhi. Trop Doct. 2008;38(1): 28-30.

11. Aggarwal A, Chandra J, Aneja S, et al. An epidemic of dengue hemorrhagic fever and dengue shock syndorme in children in Delhi. Indian Pediatr. 1998;35(8):727- 32.

12. Rachel D, Philip R, Philip AZ. A study of clinical profile of dengue fever in Kollam, Kerala, India. Dengue Bul. 2005;29:196202.

13. Ahmed S, Arif F, Yahya Y, et al. Dengue fever outbreak in Karachi 2006 - a study of profile and outcome of children under 15 years of age. J Pak Med Assoc. 2008; 58(1): 4-8.

14. Peters CJ. Infections caused by arthropodand rodent-borne viruses. In: Braunwald E,
Fauci AS, Kasper DL, et al (eds). Harrison's Principles of Internal Medicine. 15th ed. New York: McGraw Hill. 2001: Pp:115266.

15. Dengue haemorrhagic fever: diagnosis, treatment, prevention and control, 2nd ed. Geneva, Switzerland, World Health Organization, 1997.

16. Kamath SR, Ranjit S. Clinical features, complications and atypical manifestations of children with severe forms of dengue hemorrhagic fever in South India. Indian J Pediatr. 2006;73(10):889-95

17. Garacia-Rivera EJ, Rigan-Perez JG. Encephalitis and dengue. Lancet 2002; 360 (9328):261 .

18. Kankirawatana P, Chokephaibulkit K, Puthavathana $\mathrm{P}$, et al. Dengue infections presenting with central nervous system manifestations. J Child Neurol. 2000;15(8): 544-7.

19. Cam BV, Fonsmark L, Hue NB, et al. Prospective case-control study of encephalopathy in children with dengue hemorrhagic fever. Am J Trop Med Hyg. 2001;65(6):848-51.

20. Thisyakorn U, Thisyakorn C, Limpitikul W, et al. Dengue infection with central nervous system manifestations. Southeast Asian J Trop Med Publ Health. 1999;30(3):504-6.

21. Pancharoens C, Thusyakorn U. Neurological manifestations in dengue patients. Southeast Asian J Trop Med Publ Health. 2001;32(2):341-5.

22. Cam BV, Fonsmark L, Hue NB, et al. Prospective case-control study of encephalopathy in children with dengue hemorrhagic fever. Am J Trop Med Hyg. 2001;65(6):848- 51.

23. Malavige GN, Ranatunga PK, Jayaratne SD, et al. Dengue viral infections as a cause of encephalopathy. Indian J Med Microbiol. 2007;25(2):143-5. 